\title{
The Relationship between Interpersonal Relationships and Suicidal Ideation of Male Rehabilitation Protection Recipients with Alcohol Problems: The Mediating Effect of Depression
}

\author{
Won-Geon $\operatorname{Han}^{1}$,Eunsil Kim², Hyundong Son ${ }^{3}$ \\ Namseoul University Gwangju National University of Education \\ 1'gks316@naver.com, ${ }^{2}$ gender@hanmail.net, ${ }^{3}$ chamcoun@gnue.ac.kr
}

\begin{abstract}
The purpose of this study was to investigate the role of depression in the relationship between interpersonal relationships and suicide ideation among male rehabilitation protection recipients with alcohol problems. The participants of this study were 184 male rehabilitation protection recipients with alcohol problems. The tools used were AUDIT-K, Interpersonal Needs Questionnaire-Revised, Scale for Suicide Ideation-Beck, and Beck Depression Inventory-K. The results were that depression played a partial mediator role in interpersonal relationships and suicidal ideation.
\end{abstract}

Keywords: Interpersonal Relationships, Suicide Ideation, Depression, Male Rehabilitation Protection Recipients, Alcohol Problems.

\section{Introduction}

Many prisoners return to their communities after their release, but their recidivism is high. The reason is that they have many stressors such as family dismemberment, discord, social exclusion, stigma, and economic difficulties. As a result, they are more likely to experience behavior problems such as decreased self-esteem, lethargy, depression, and anxiety, as well as increased violence and suicide [1][2][3]. Alcohol use is one of the accessible choices among ex-offenders to escape from these various difficulties and psychological distress [4][5][6][7]. Several studies have shown that the prevalence of alcohol use is high among ex-offenders [8][9]. However, the drinking of ex-offenders is pointed out as a risk factor of recidivism [5][10]. Besides, the risk of problem drinking can cause severe problems such as suicide ideation and suicide attempts [11][12][13][14]. Drinking is a risk factor and a trigger factor for predicting suicide[15][16]. These results imply that male rehabilitation protection recipients with alcohol problems are also exposed to suicide risk.

The difficulty of the interpersonal relationship is being treated as an essential factor to increase suicide ideation [17][18][19][20]. Also, depression has been reported to be a vital risk factor for suicide, including suicide and suicidal behavior [21][22][23]. Moreover, male rehabilitation protection recipients were significantly more depressed than the general population [1]. On the other hand, interpersonal relationships have been reported to be an essential and robust predictor of depression and suicide [24]. Interpersonal issues and adverse interpersonal events significantly increase the risk of depression and suicide [25]. Furthermore, the results of the previous studies on the structural relationship between depression,

Article history:

Received (April 19, 2019), Review Result (June 24, 2019), Accepted (August 29, 2019) 
interpersonal relationship, and suicidal ideation show that the interpersonal relationship, depression, and suicidal ideation have direct and indirect effects, and depression has a partial mediating effect between interpersonal relationship and suicide ideation [26][27].

Although depression, interpersonal problems, and suicide are common problems among the male rehabilitation protection recipients with alcohol problems, there are few studies on suicide. The purpose of this study was to investigate the interpersonal relationship among the male rehabilitation protection recipients with alcohol problems and to identify the role of depression in the relationship between interpersonal relationships and suicide ideation.

\section{Methods}

\subsection{Participants}

The participants of this study were male rehabilitation protection recipients with alcohol problems who were using the welfare service in the Gyeonggi Provincial Office of Korea Rehabilitation Agency. Among them, 184 males aged 18 years or older who had drinkingrelated problems and agreed to the survey were sampled. The data were collected according to a procedure approved by the Institutional Review Board of Namseoul University. The survey period was from October 23, 2018, to November 16, 2018.

\subsection{Tools}

Four instruments were used as a tool. First, AUDIT-K which was translated and validated by Lee et al. [28] was used. Cronbach's $\alpha$ of AUDIT-K in this study was .83. Second, Interpersonal Needs Questionnaire Revised (INQ-R)[29] is a thirty items self-report scale to measure frustrated feeling of belonging and feelings of burden. In this study, the Cronbach's $\alpha$ was .95. Third, Scale for Suicide Ideation-Beck (BSSI) is a 19-item clinical research instrument designed to quantify and assess suicidal intention [30]. In this study, the Korean version of BSSI translated and modified to self-reporting questionnaire by Shin et al. [5]. Cronbach's $\alpha$ of BSSI in this study was .94. Fourth, Beck Depression Inventory-Korean Version (K-BDI) adapted by Lee and Song [31] was used. Cronbach's $\alpha$ of K-BDI in this study was 89 .

\subsection{Data Analysis}

To test the mediating effect of depression in the relationship between interpersonal and suicide ideation, the procedure of Baron and Kenny [32] using regression analysis was used. First, the statistical significance of the interpersonal relationship (independent variable) on

suicide ideation (dependent variable), was first examined. Then the statistical significance of the effects of interpersonal relationships on depression (mediating variable) was examined. In the next step, the statistical significance of the effects of mediators on dependent variables was examined. In the last step, the statistical significance of the effects of independent variables on dependent variables was tested after controlling the effects of mediating variables. At this time, we confirmed that the influence of the independent variable appears less than the previous step. When the influence of independent variables on the dependent variables was significant, we call it as partial mediation. On the other hand, when it was not significant, we call it as full mediation. The statistical significance of these mediating effects was tested by Sobel's Z-test. Sobel[33] asserted that the mediating effect is statistically significant if the $Z$ value is greater than 1.96 or less than -1.96 . All data were analyzed using SPSS version 25.0. 


\section{Results}

Table 1 shows the correlation and descriptive statistics among the main variables. Alcohol problems positively correlated with interpersonal relationships and depression, and moderate positively correlated with suicide ideation. Suicide ideation showed a moderate positive correlation with interpersonal relationships and a weak positive correlation with depression. There was a weak positive correlation between interpersonal relationships and depression.

Table 1. Correlation between Variables and Descriptive Statistics

\begin{tabular}{lcccc}
\hline & $\begin{array}{c}\text { Alcohol Probl } \\
\text { em }\end{array}$ & $\begin{array}{c}\text { Interpersonal } \\
\text { Relationships }\end{array}$ & $\begin{array}{c}\text { Suicide Idea } \\
\text { tion }\end{array}$ & Depression \\
\hline $\begin{array}{l}\text { Interpersonal Relations } \\
\text { hips }\end{array}$ & $.37^{* * *}$ & - & - & - \\
Suicide Ideation & $.40^{* * *}$ & $.53^{* * *}$ & - & - \\
Depression & .13 & $.22^{* * *}$ & $.33^{* * *}$ & - \\
\hline \multicolumn{1}{c}{$M$} & 25.78 & 146.37 & 18.11 & 28.73 \\
\multicolumn{1}{c}{$S D$} & 6.82 & 44.56 & 7.50 & 7.96 \\
\hline
\end{tabular}

Note. ${ }^{* * *}>001$.

As a result of following the steps of Baron and Kenny (1986), depression partially mediates the effect of interpersonal relationships on Suicide Ideation (see Table 2). The results of the Sobel test ( $Z=3.277,>$ <1) on the mediation effect were also statistically significant. [Figure $1]$ shows the model of this study results.

Table 2. Mediating Effects of Depression in the Relationship between Interpersonal Relationships and Suicide Ideation

\begin{tabular}{cccccc}
\hline Step & Dependent Variable & Independent Variable & $\beta$ & $R^{2}$ & $F$ \\
\hline 1 & Suicide Ideation & Interpersonal Relationship & $.534^{* * *}$ & .286 & $72.767^{* * *}$ \\
\hline 2 & Depression & Interpersonal Relationship & $.224^{* *}$ & .050 & $9.630^{* *}$ \\
\hline 3 & Suicide Ideation & Depression & $.306^{* * *}$ & .106 & $21.478^{* * *}$ \\
\hline 4 & Suicide Ideation & $\begin{array}{c}\text { Interpersonal Relationship } \\
\text { Depression }\end{array}$ & $\begin{array}{c}.486^{* * *} \\
.216^{* * *}\end{array}$ & .330 & $44.561^{* * *}$ \\
\hline
\end{tabular}

Note. ${ }^{* * *}>001$.

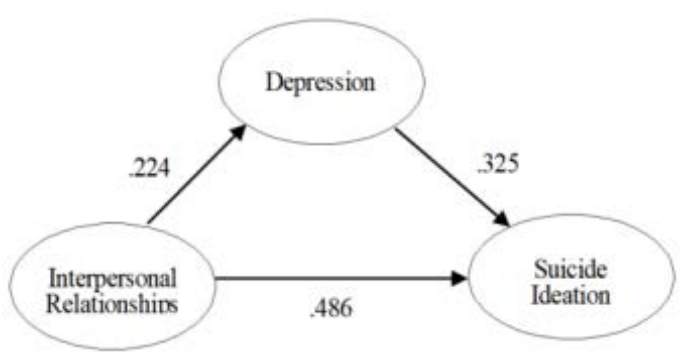

Figure 1. The Model of Mediating Effects of Depression in the Relationship between Interpersonal Relationships and Suicide Ideation 


\section{Conclusions}

The purpose of this study was to investigate the prevalence of alcohol problems, suicide ideation, depression, interpersonal relationships among the male rehabilitation protection recipients with alcohol problems and the role of depression in the relationship between interpersonal relationships and suicide ideation.

First, participants of this study have severe alcohol problems, suicide ideation, and depression. This finding is consistent with the results of a survey[34] that suicide was associated higher among ex-offenders than the general population. Therefore, Korea Rehabilitation Agency should actively prevent and intervene in committing suicide among the male rehabilitation protection recipients with alcohol problems.

Second, depression was found to play a partial mediating role in the relationship between interpersonal relationships and suicide ideation. In other words, the more frustrated the interpersonal relationship desire, the more depressed. So it affects suicide ideation to increase. This result is consistent with the previous study [35] which reported that depression plays a mediating role. Therefore, to prevent the suicide ideation of the male rehabilitation protection recipients with alcohol problems, there is a need for intervention to deal with interpersonal relationships, depression, and suicide comprehensively and continuously. Also, it is necessary to specialize and expand the system, such as therapeutic custody, outpatient treatment order, and indictment suspension.

\section{Acknowledgements}

This manuscript is a partial amendment of the master's thesis by Won-Geon Han (2018).

\section{References}

[1] K. H. Choi, S. W. Kim, H. M. Lim, S. Y. Kim, K. S. Jeon and S. S. Oh, "Development of korea psychological health inventory for released convicts”. Correction Welfare Studies, (2017), Vol.49, pp.195-230.

[2] S. Belenko, “Assessing released inmates for substance-abuse-related service needs”. Crime \& Delinquency, (2006), Vol.52, No.1, pp.94-113.DOI: 10.1177/0011128705281755

[3] C. Brooker, C. Sirdifield, R. Blizard, D. Denney and G. Pluck, "Probation and mental illness". Journal of Forensic Psychiatry \& Psychology, (2012), Vol.23, No.4, pp.522-537. DOI: 10.1080/14789949.2012.704640

[4] J. S. Kim and S. K. Chung, "The influence of mental health and drinking on crime recidivism among probationers”. Mental Health \& Social Work, (2015), Vol.43, No.3, pp.35-57.

[5] M. S. Shin, K. B. Park, K. J. Oh and Z. S. Kim, “A study of suicidal ideation among high school students: The structural relation among depression, hopelessness, and suicidal ideation”. Korean Journal of Clinical Psychology, (1990), Vol.9, No.1, pp.1-19.

[6] D. H. Lee and K. Y. Bang, "Ex-offenders` experiences regarding reintegration into society and family”. Korea Journal of Counseling, (2014), Vol.15, No.6, pp.2645-2666.

[7] E. J. Khantzian, "Psychological (structural) vulnerabilities and the specific appeal of narcotics". Annals of the New York Academy of Sciences, (1982), Vol.398, pp.24-32.

[8] Ministry of Health and Welfare (2017). 2016 The prevalence of mental disorder. Seoul: Author.

[9] M. S. Yoon, S. Chung and S. B. Lee, "Effect of alcohol related factors on malicious crime”. Journal of Korean Alcohol Science, (2013), Vol.14, No.2, pp.49-64.

[10] A. Diehl, S. C. Pillon, M. A. dos Santos, G. H. Rassool and R. Laranjeira, "Sexual dysfunction and sexual behaviors in a sample of Brazilian male substance misusers”. American Journal of Men's Health, (2016), Vol.10, No.5, pp.418-427. DOI: 10.1177/1557988315569298 
[11] J. D. Hawkins, R. F. Catalano and J. Y. Miller, "Risk and protective factors for alcohol and other drug problems in adolescence and early adulthood: implications for substance abuse prevention”. Psychological Bulletin, (1992), Vol.12, No,1, pp.64.

[12] R. C. Kessler, G. Borges and E. E. Walters, "Prevalence of and risk factors for lifetime suicide attempts in the National Comorbidity Survey”. Archives of General Psychiatry, (1999), Vol.56, No.7, pp.617-626.

[13] N. J. Osgood and A. A. Manetta, "Substance Abuse and Suicidal Behavior inWomen Ages 30 to 39 Years”. Advances in Social Work, (2002), Vol.3, No.2, pp.158-167.

[14] A. Roy, "Distal risk factors for suicidal behavior in alcoholics: replications and new findings". Journal of Affective Disorders, (2003), Vol.77, No.3, pp.267-271.

[15] M. S. Yoon, “Suicidal ideation among alcoholics moderating effect of alcohol use”. Mental Health Social Work, (2011), Vol.38, pp.113-140.

[16] [16] R. Maris, A. Berman, J. Maltsberger and R. Yufit, “Assessment and prediction of suicide”. In This volume is based on a workshop entitled" Assessment and Prediction of Suicide" held at the 1990 annual meeting of the American Association of Suicidology (ASS) in New Orleans, Louisiana.. Guilford Press, (1992).

[17] A. R. Park and J. S. Chun, “A Study on relationship between interpersonal relationships and suicide ideation among Alcoholics: Focusing on the mediating effects of depression”. Health and Social Welfare Review, (2014), Vol.34, No.1, pp.379-407.

[18] A. K. Berman, D. A. Jobes and M. M. Silverman, “Adolescent suicide: Assessment and intervention”. American Psychological Association, (2006)

[19] S. Darke and J. Ross, “Suicide among heroin users: rates, risk factors and methods”. Addiction, (2002), Vol.97, No.11, pp.1383-1394.

[20] S, A. Kidd and M. J. Kral, “Suicide and prostitution among street youth: A qualitative analysis”. Adolescence, (2002), Vol.37, No.146, pp.411.

[21] S. K. Kahng, "Does depression predict suicide? : Gender and age difference in the relationship between depression and suicidal attitudes”. Korean Journal of Social Welfare Studies, (2010), Vol.41, No. 2, pp.67-100.

[22] K. S. Kim and Y. S. Chun, "The Effects of Depression, Anxiety, and Impulsiveness on Suicidal Thoughts among Adolescents”. Korean Journal of Human Ecology, (2012), Vol.21, No.5, pp.903-913.

[23] L. L. Harlow, M. D. Newcomb and P. M. Bentler, "Depression, self-derogation, substance use, and suicide ideation: Lack of purpose in life as a mediational factor”. Journal of Clinical Psychology, (1986), Vol.42, No.1, pp.5-21.

[24] T. E Joiner Jr, K. A. Van Orden, T. K. Witte, E. A. Selby, J. D. Ribeiro, R. Lewis and M. D. Rudd, "Main predictions of the interpersonal-psychological theory of suicidal behavior: Empirical tests in two samples of young adults”. Journal of Abnormal Psychology, (2009), Vol.118, No.3, pp.634-646.

[25] T. E. Joiner Jr and M. D. Rudd, "Negative attributional style for interpersonal events and the occurrence of severe interpersonal disruptions as predictors of self-reported suicidal ideation”. Suicide and Life-Threatening Behavior, (1995), Vol.25, No.2, pp.297-304.

[26] B. K. Park, “An Analysis of the Developmental Path of Adolescent` Depression and Suicidal Ideation”. Mental Health \& Social Work, (2009), Vol.31, pp.207-235.

[27] E. M. Kleiman, R. T. Liu and J. H. Riskind, "Integrating the interpersonal psychological theory of suicide into the depression/suicidal ideation relationship: A short-term prospective study”. Behavior Therapy, (2014), Vol.45, No.2, pp.212-221.

[28] C. K. Kim, S. Y. Lee and W. Y. Choi, "Effectiveness of a depression and suicide intervention program for children with depression and suicide thought”. The Korean Society of Emotional and Behavioral Disorders, (2005), Vol. 21, No.1, pp.169-191.

[29] K. A. Van Orden, “Construct validity of the Interpersonal Needs Questionnaire. Doctoral Dissertation”, Florida State University, (2009)

[30] A. T. Beck, M. Kovacs and A. Weissman, “Assessment of suicidal intention: the Scale for Suicide Ideation”. Journal of Consulting and Clinical Psychology, (1979), Vol.47, No.2, pp.343. 
[31] Y. H. Lee and J. Y. Song, “A study of the reliability and the validity of the BDI , SDS, and MMPI-D Scales”. The Korean Journal of Clinical Psychology, (1991) Vol.15, No.1, pp.98-113.

[32] R. M. Baron and D. A. Kenny, “The moderator-mediator variable distinction in social psychological research: Conceptual, strategic, and statistical considerations”. Journal of personality and social psychology, (1986), Vol.51 No.6, pp.1173.

[33] M. E. Sobel, “Asymptotic confidence intervals for indirect effects in structural equation models”. Sociological Methodology, (1982), Vol.13, pp.290-312.

[34] I. A. Binswanger, M. F. Stern, R. A. Deyo, P. J. Heagerty, A. Cheadle, J. G. Elmore \& T. D. Koepsell, “Release from prison-a high risk of death for former inmates”. New England Journal of Medicine, (2007), Vol.356, No.2, pp.157-165.

[35] A. R. Park and J. S. Chun, "A study on relationship between interpersonal relationships and suicide ideation among alcoholics: focusing on the mediating effects of depression”. Korean Ins Health Society Affairs, (2014), Vol.34, No.1, pp.379-407.

\title{
Authors
}

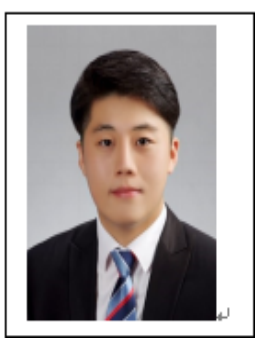

\author{
Won-Geon Han \\ Counselor in Korea Center On Gambling Problems \\ Mental Health Social Worker
}

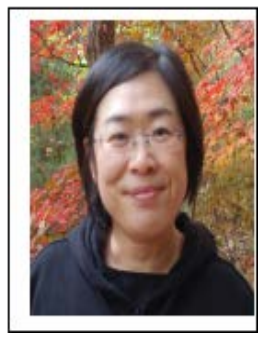

\section{Eunsil Kim}

Assistant Professor in Namseoul University Child Welfare

Chief Manager in Namseoul University Student Counseling Center

Director of Addiction Rehabilitation Counseling Program in Namseoul University Graduate School

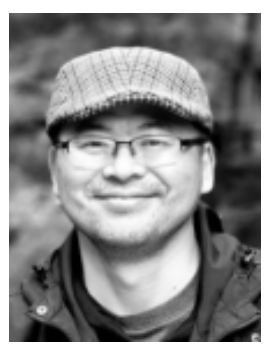

\section{Hyun-Dong Son}

Professor in Gwangju National University of Education 